\title{
RESULTS AND FINDINGS FROM 15 YEARS OF SUSTAINABLE URBAN STORM WATER MANAGEMENT
}

\author{
JOACHIM SARTOR, MIRKA MOBILIA \& ANTONIA LONGOBARDI \\ Department of Civil Engineering, Trier University of Applied Sciences, Germany. \\ Department of Civil Engineering, University of Salerno, Italy.
}

\begin{abstract}
In accordance with the latest German regulations, the basic idea of the project "Sustainable Urban Storm Water Management", funded by the Trier University of Applied Sciences, Germany, is to restore the natural water balance in urban areas to avoid the widely recognized disadvantages of runoff from impervious surfaces. To improve the components of such concepts and their hydrological simulation approaches, a one-family house in Western Germany was monitored in this respect over 15 years (1998-2012). It comprised a green roof, as well as storm water infiltration and utilization. Measurements included precipitation and runoff. This data set was used for calibration of storm-runoff model approaches with increasing complexity and for simulation of hydrological green roof performance under different climate conditions (local and Mediterranean). Also, a long-term simulation using differing arrangements was conducted, e.g. linkage of additional storm water from a pitched concrete roof to the green roof. The investigations revealed that the most relevant model component in hydrological green roof simulation is the calculation of the evapotranspiration process. Some results could be checked against values from German regulations. The most relevant practical findings are that the green roof proved itself to be an excellent "filter" for the storm water utilization tank and that the linkage between a pitched roof section and the green roof proved its worth providing additional water supply for the vegetation in rain-scarce periods, as well as a retention facility during heavy storm events.

Keywords: evaporation calculation, hydrological green roof behaviour, storm water utilization, urban storm water management, water balance simulation.
\end{abstract}

\section{INTRODUCTION}

The basic concept of the project "Sustainable Urban Storm Water Management" [1], is to restore or reachieve the natural water balance in urban areas. This is to avoid the widely recognized disadvantages of impervious surfaces in combination with conventional urban storm drainage, such as

- exacerbation of floods and droughts in the receiving water

- decreased groundwater recharge

- changes in the local micro climate (less evapotranspiration, rise in surface temperature, dust generation).

The latest German regulations [2, 3] and [4-7] also include the natural water balance as a criterion in the evaluation of the degree of sustainability of storm water management concepts. Thus, concepts are favored, which may consist of measures such as

- prevention of urban runoff by minimizing sealed surfaces

- storm water infiltration and utilization

- green or retention roofs.

Unfortunately, in addition to minimizing sealed surfaces in new development areas, in practice, such concepts currently focus solely on storm water infiltration. This is mainly for 
economic reasons, because the disconnected areas do not need to be considered in the design of storm sewer systems. It is shown by Sartor [8], through simple water budget calculations, that using pure infiltration measures, due to the widely dispensed evaporation component, the underground is burdened with 2- to 7-times the amount of water as under the land-use conditions prior to sealing. There are cases of such infiltration facilities that do work and some that do not for the above- mentioned reason, in addition to other factors (e.g. soil compaction during construction). Impacts on residents of the developed area in those cases range from general moisture problems to landslides. However, by positioning a green roof or a storm water utilization tank before the infiltration facility, the natural water balance can largely be met on an annual basis. Thus, the water holding capacity of the soil can be increased and, under ideal conditions, there will be no exacerbation of floods in the receiving water.

\section{CONCEPT OF THE PROJECT}

\subsection{Objectives and subject of investigations}

To improve the components of such concepts and their hydrological simulation approaches, a one-family house in Western Germany near Bernkastel-Kues was monitored in this respect over 15 years (1998-2012). It comprises an extensive green roof as well as storm water infiltration and utilization. Measurements included precipitation (continuously) and runoff (daily time steps) at three cross sections. At the start of the investigations in 1997 these components can be described in detail as follows (Figs 1 and 2).

- Pitched roof area $\mathbf{I}: \mathrm{A}_{\mathrm{I}}=41 \mathrm{~m}^{2}$; runoff through vortex filter to storm water utilization facility with contents measurement of its tank

- Pitched roof area II: $\mathrm{A}_{\mathrm{II}}=25 \mathrm{~m}^{2}$; runoff as at I

- Pitched roof area III: $\mathrm{A}_{\mathrm{III}}=32 \mathrm{~m}^{2}$; runoff divertable to sewer system or green roof

- Pitched roof area IV: $A_{I V}=34 \mathrm{~m}^{2}$; runoff to measurement tank (volume V = 200 litre); usage for garden irrigation or similar; overflow to sewer system

- Green roof: $\mathrm{A}=22 \mathrm{~m}^{2}$; extensively greened flat roof, depth of growing medium $15 \mathrm{~cm}$; runoff to measurement tank (500 litre); usage for garden irrigation or similar; overflow to infiltration facility (Fig. 3)

- Storm water utilization facility: 1500 litre tank (corresponding to 23 litre per $\mathrm{m}^{2}$ roof area); supplying 2 toilets (from 3 in total), washing machine and external tap; tank overflow to infiltration facility

- Infiltration facility: Trough with a depth of about $25 \mathrm{~cm}$ with $\mathrm{V}$ ca. $1 \mathrm{~m}^{3}$ and gravel-filled drain trench underneath $\left(\mathrm{V}_{\text {gross }}\right.$ ca. $\left.8 \mathrm{~m}^{3}\right)$

- Precipitation measurement: Recording rain gauge, registration on EDP-storage and paper; check of total depths by electronic device and collection box as well as by separate simple rain gauge on the green roof.

Highest priority in the monitoring concept had the continuous precipitation measurement, including different secondary control devices. On the other hand, a continuous flow measurement at the three cross-sections appeared too costly with respect to operations and maintenance, as well as to capital costs. Therefore, a simple flow measurement by reading the actual water level in the tanks was conducted on a daily basis. Due to the limited volume of a 500 litre tank below the green roof, its overflow was unavoidable during heavy storm events. 


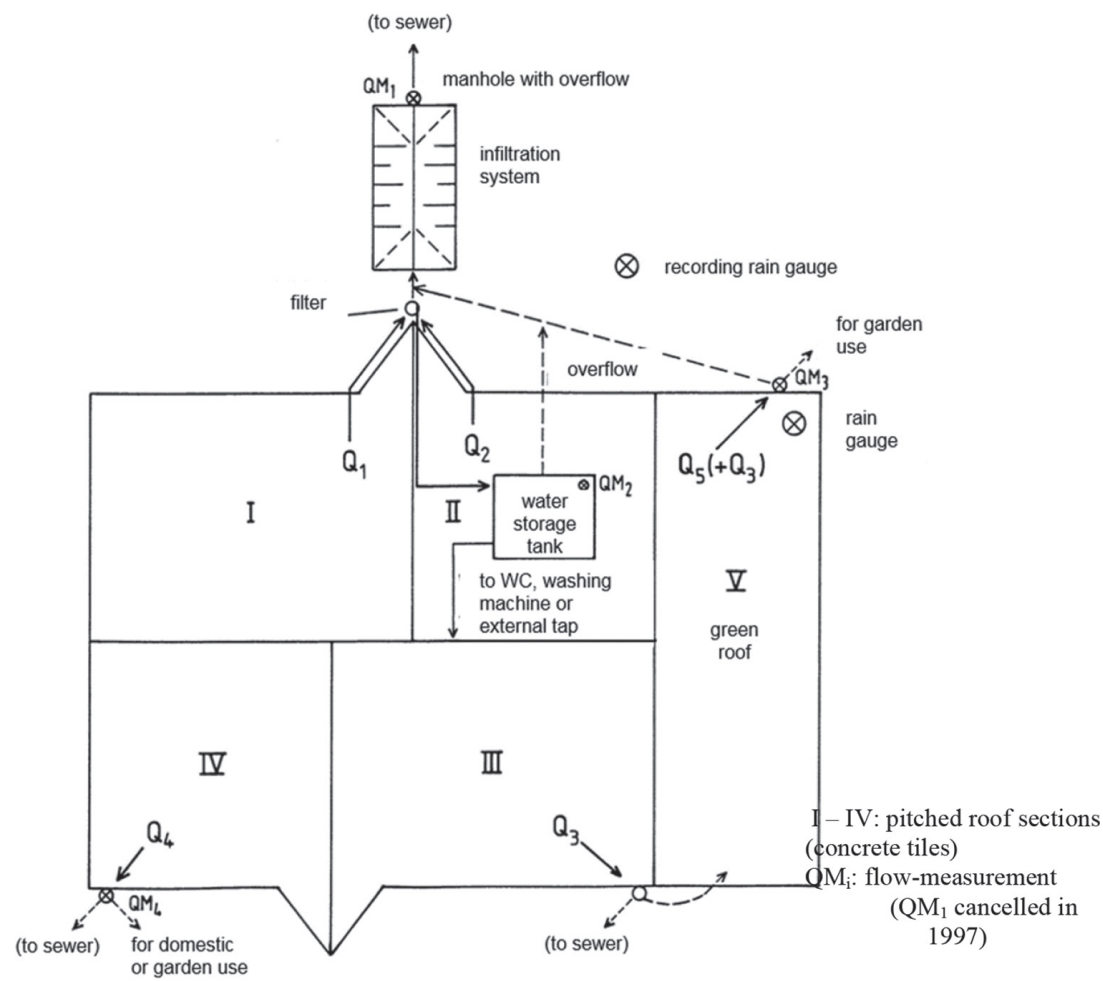

Figure 1: Layout of the subject of investigations (1-family house) with measurement arrangements in 1997

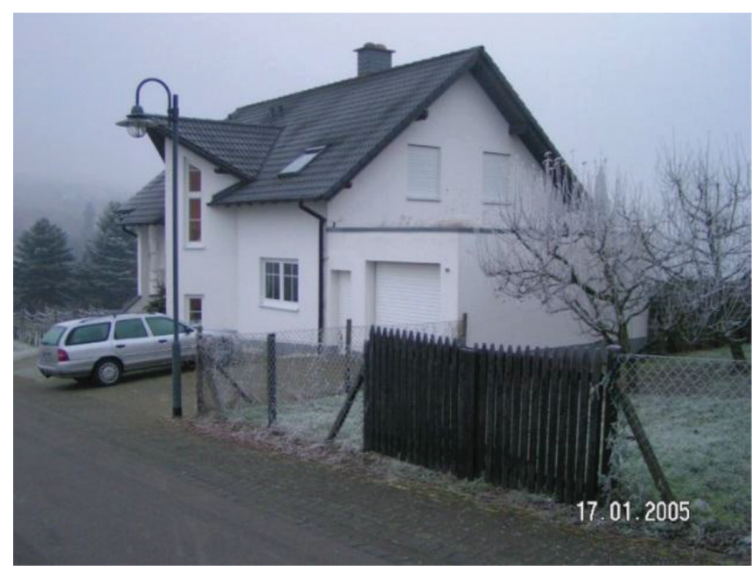

Figure 2: Overall view (garage with green roof in the foreground)

The data gaps caused were filled by a storm-runoff simulation. A prerequisite was sufficient monitored events to calibrate model parameters.

One focus of the investigations was the hydrological behaviour of the green roof. Its vegetative layer is made of sedum and spontaneous vegetation. Maintenance is limited to a yearly check for unwanted tree/brush growth. 


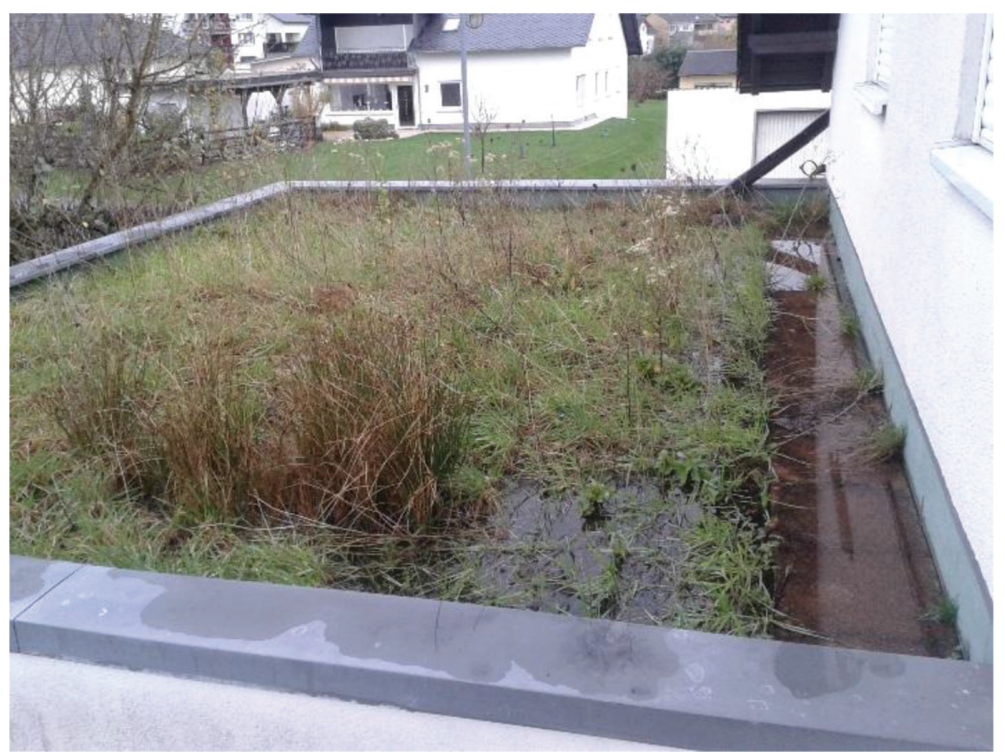

Figure 3: Green roof after loading with nearly $31 \mathrm{~mm}$ of precipitation over about 3 days (in the right background is the connecting pipe from the pitched roof)

A close cooperation with the Italian University of Salerno has been maintained since 2014. Due to serious flash floods in the recent past there is great interest in Italy in flow-reduction measures for urban areas.

\subsection{Detailed study of storm water transfer over a green roof}

The aforementioned measures to disconnect existing sealed surfaces from urban drainage systems are often limited by the following problem: It is usually difficult to link pitched roof sections that are directed to the street, to an infiltration facility, which is mostly located in the garden on the backside of a house (Fig. 4). Typically, many one- or two-family houses (at least in Germany) have an additional box-like garage connected to one side. Thus, storm water from the usually higher-located pitched roof can easily be transferred over the (greened) flat roof to the infiltration facility in the garden to achieve the above-mentioned advantages with respect to the overall water balance. In those cases, the question arises whether a significant reduction of the additional water from the pitched roof $\left(\mathrm{Q}_{\mathrm{ST}}\right.$ in Fig. 4) through evaporation $(\Delta \mathrm{E})$ on the green roof can be taken into account in the design of the infiltration facility.

\section{PRACTICAL EXPERIENCES AND RESULTS}

\subsection{Course of investigations and practical findings}

At an early stage of the project, it was recognized that the storm water utilization tank often runs empty. This was caused by the specified value of only 23 litre per $\mathrm{m}^{2}$ roof area being significantly lower than the recommended volume of 25 to 50 litre per $\mathrm{m}^{2}$ roof area [9]. 


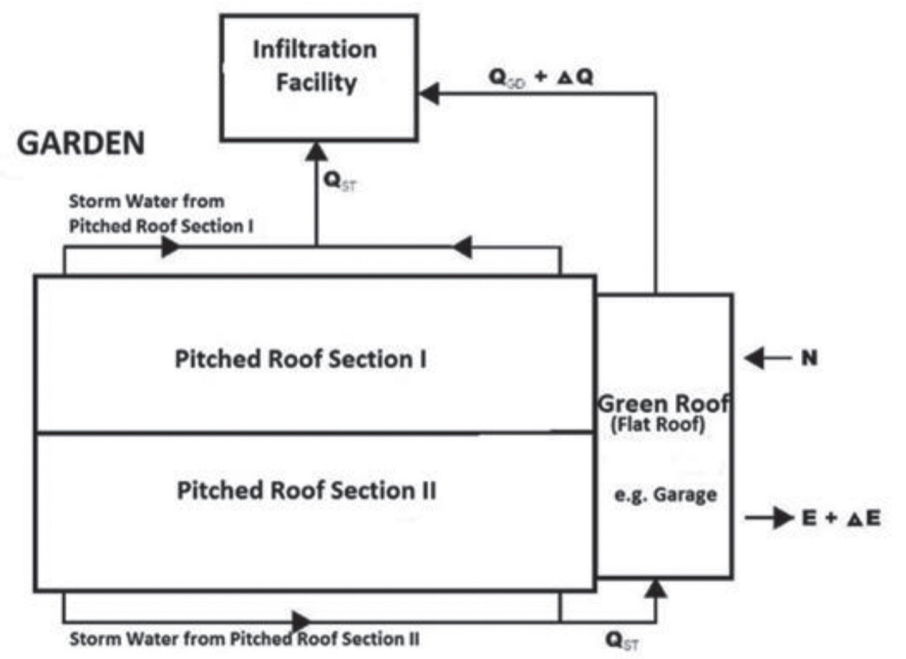

STREET

$\mathrm{Q}_{\mathrm{ST}}$ : Runoff from pitched roof; $\mathrm{Q}_{\mathrm{GD}}$ : Runoff from green roof

N: Precipitation; E: Evaporation (of $N$ )

$\Delta \mathrm{E}$ : Additional evaporation of $\mathrm{Q}_{\mathrm{ST}} ; \Delta \mathrm{Q}=\mathrm{Q}_{\mathrm{ST}}-\Delta \mathrm{E}$

Figure 4: Transfer of storm water from a pitched roof section, directed to the street, over a sideward green roof to an infiltration facility in the rear of a one-family house

Because of the following problems, the initially-provided structural option to double this volume was cancelled. For one, frequent clogging of the micro-screen of the washing machine was experienced. The machine was supplied by storm water taken primarily from the tank bottom where settled particles were also suctioned in. These originated from bird faeces and moss, washed down from the unsealed concrete tiles of the pitched roof. The vortex filter at the tank inlet proved ineffective and is generally not further recommended. A related problem was the periodically occurring odour from decomposition of the storm water, which resulted from biological degradation of the above-mentioned particles in the tank.

As a result, after about one year of operation, the washing machine was disconnected from the storm water utilization tank and connected to the public water supply. Also, the water tap in the garden was never used in practice. In addition, in 2009 the storm water tank was disconnected completely from the pitched roof, since the decomposition problem was unresolved despite periodical addition of sulfur. Instead, the overflow tank below the green roof was directly connected to the storm water utilization tank.

Some effects became apparent after the end of the measurement period. In particular, the direct connection of the overflow tank to the storm water utilization tank was generally successful. A green roof can be recommended as an excellent "filter" with respect to water quality. Also with respect to quantity, the combination of a green roof ( $22 \mathrm{~m}^{2}$ area) with the additional storm water from a pitched roof of $32 \mathrm{~m}^{2}$ appears as an ideal solution in this case, because the 1500 litre storm water tank seldom went dry or overflowed. However, it must also be taken into account that the number of persons utilizing this water has decreased from an initial four down to the present two.

The connection of the pitched to the green roof was also advantageous for its vegetation. E.g. during the rain-scarce period in spring and early summer of 2017 , the roof vegetation 


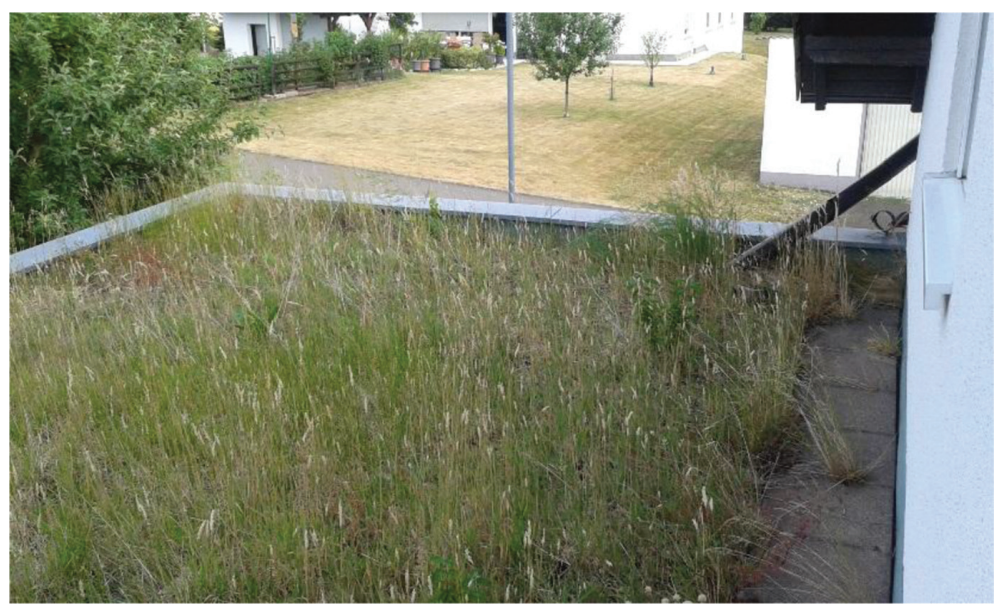

Figure 5: Condition of the green roof on 23 June 2017 after a long rain-scarce period. Compare its colour with that of the lawn in the background (on the right side is the connecting pipe from the pitched roof)

showed relatively few problems when compared to natural vegetation. The additional water from the pitched roof section during the few, mostly light rain events was obviously sufficient (Fig. 5).

\subsection{Quantitative results}

\subsubsection{General}

Student theses demonstrated that the restoration of the natural water balance can be roughly met by using the aforementioned components (with theoretical variation in size). Of course this could only be demonstrated using a simulation model that was calibrated by the measured project data. Corresponding to these data, a time step of one day was generally used.

One result was the establishment of a mean daily drinking water savings through the storm water utilization facility, which was calculated to be 20 litre p.p. for the period from 1998 to 2001. For this relatively small value, it must be considered that the tank volume was comparably small (see section 3.1) and that only two of three toilets in the house were supplied. During that time period, the house was occupied by a family of four. Over time, number of persons was gradually reduced to two. Thus, the savings values are no longer comparable to one another.

\subsubsection{Storm-runoff simulation}

Since the simulation of storm water runoff from roof areas into a storm water harvesting tank does not usually generate serious problems, the focus of this study was the modelling of the hydrological green roof behaviour. The complexity of the associated simulation approaches was gradually increased. Basically, however, a daily balance of the water content $V$ of the green roof was conducted taking into consideration the precipitation input and the evaporation output in relation to the content $V$ of the previous day. Overflow, with respect to runoff $Q$, was only calculated if the maximum water holding capacity $W_{\max }$ of the green roof was exceeded. 
Early in the study it was realized that the most relevant model component is the calculation of the evapotranspiration process, since it determines the soil moisture at the start of an event and thus determines the potential storage of storm water in the green roof. The importance of the antecedent soil moisture conditions is also underlined by Uhl et al. [10] and Schere et al. [11].

As the simplest approach to calculate the potential evaporation $E_{P}$, the formula from Brandt [12] was used:

$$
E_{p}=1.4 \sin \left[\frac{2 \pi}{365}(j-91)\right]+1.8[\mathrm{~mm} / \text { day }]
$$

where $j$ : day of the year ( 1 January: $j=1$ )

This led not to the real, but to that evaporation that occurs in an average year in Germany on the day " $j$ ". According values vary between 0.4 and $3.2 \mathrm{~mm}$ per day.

To improve on this value, the following approach from Haude [13] was used for the determination of daily evaporation values.

$$
E_{P}=f \cdot\left(e_{S}-e\right)=f \cdot e_{S}(1-\mathrm{RF})[\mathrm{mm} / \mathrm{day}]
$$

where $\left(e_{S}-e\right)$ : saturation vapor pressure deficit of the air at 2:30 pm [hPa]

RF: relative humidity at 2:30 pm [-]

$f: \quad$ Haude coefficient. Values vary between 0.22 (October - March) and 0.29 (April/May)

In this case, actual daily data of humidity RF and temperature $T$ (to calculate the saturation vapor pressure $e_{S}$ ) were used, but this improvement did not really pay off. All evaporation values, calculated from different combinations of these data, were (on average) approximately between $-53 \%$ (daily mean values of RF and $T$ ) and $+25 \%$ (RF at $2 \mathrm{pm}$ and max daily $T$ ) of the values from Penman, that are recommended by the Food and Agriculture Organization of the $U N O$ and have been offered on the internet [14] since 2009. As a consequence, thereafter only evaporation values from Penman were used. However, as a result of this decision, simulations were limited to the period from 2009 to 2012.

For all simulations to date, the potential evaporation $E_{P}$ was equated to the actual evaporation $E_{a}$, provided that the calculated water content $V$ of the green roof was sufficient to supply it. For all further investigations the water budget simulation was improved by calculating the actual evaporation as a function of the actual water content $V$ :

$$
E_{a}=E_{P} \quad V / W_{\max } \quad[\mathrm{mm} / \mathrm{d}]
$$

Herewith it should be considered that plants reduce their transpiration with decreasing water content and only at saturation $\left(V=W_{\max }\right)$ will the potential evaporation equal the actual one.

To limit the length of this paper, all following results refer to the later and most complex state of the model, if not otherwise stated.

For calibration of the maximum water holding capacity $W_{\max }$, in-total 20 events were used for which the measurements appeared particularly reliable. This led to relatively small events, which generated no overflow of the measurement tank (500 litre) below the green roof. Nevertheless this was advantageous because in this way events were analysed which were on the magnitude of the green roof's capacity to handle storm events. As a first step, 10 events were 
used from the roughly 4-year-period during which no pitched roof section was linked to the green roof. This led to a value of $W_{\max }=39 \mathrm{~mm}$. For the period with additional water from the pitched roof section, 10 further events were selected and simulated, considering the measured initial loss of $0.4 \mathrm{~mm}$ for the pitched roof. Because the value of $W_{\max }=39 \mathrm{~mm}$ was not changed, this second stage may be seen as a kind of validation in a wider sense. Accumulated positive and negative discrepancies between measured and simulated values were near zero for both systems. Nevertheless it must be stated that for some events simulation results were not satisfying. In addition, the calibrated value $W_{\max }=39 \mathrm{~mm}$ lies slightly below the ideal range of 46 to $75 \mathrm{~mm}$ according to Ref. [15].

It can be summarized here that further model improvement appears necessary and thus further research efforts are required. But this not only applies to these relatively simple approaches. Even with more complex models like the Storm Water Management Model (SWMM), the simulation of hydrological green roof behavior causes serious problems according to a study at the Münster University of Applied Sciences, Germany.

With the calibrated model, a yearly runoff coefficient of 0.431 was achieved for the 4-year-period from 2009 to 2012 . This fits remarkably well with the corresponding empirical value of 0.423 from Ref. [2].

\subsubsection{Transfer of storm water over a green roof}

This part of the study was conducted with the above described model for the period from 2009 to 2012. For the system without pitched roof connection, with the mean annual precipitation depth of $704.9 \mathrm{~mm}$, an actual evaporation depth of $E_{a}=400.8 \mathrm{~mm}$ was calculated. For the alternative system, long-term simulation led to an additional burden on the green roof of $\mathrm{Q}_{\mathrm{ST}}=931.3 \mathrm{~mm} / \mathrm{a}$ by water from the pitched roof (Fig. 4). According to the model $\Delta \mathrm{E}=76.5$ $\mathrm{mm} / \mathrm{a}$ of $\mathrm{Q}_{\mathrm{ST}}$ were additionally evaporated. Seen as a fraction of the additional water from the pitched roof, a relative evaporation of $\Delta \mathbf{E}=\mathbf{( 7 6 . 5 / 9 3 1 . 3}=) \mathbf{8 . 2 \%}$ was achieved.

Thus, in this case, through the storm water transition from a pitched over a green roof in an average year, about $\Delta \mathbf{E}=\mathbf{8 \%}$ from this additional water evaporates and a downstream infiltration facility will be relieved by the same amount. But without further investigation, including single events, this value should not be considered for actual design. However, this provides a conservative design value with additional reserves.

\subsubsection{Hydrological green roof performance under different climate conditions}

To investigate different climate conditions (local and Mediterranean), weather data from the monitored green roof, located near Bernkastel-Kues in Western Germany and from Salerno in Southern Italy were used for long-term seasonal and single event simulations of a virtual green roof [16]. Its depth was chosen as $15 \mathrm{~cm}$ and its parameter $W_{\max }$ as $65 \%$ (97.5 mm). The rather oceanic climate of Western Germany is characterized by warm (but not hot) summers and cool (but not cold) winters whereas the Mediterranean climate generally features warm to hot, dry summers and mild to cool, wet winters. For the investigated period from 2004 to 2007, the mean annual precipitation depths are $608 \mathrm{~mm}$ near Bernkastel-Kues and $1220 \mathrm{~mm}$ in Salerno. Roughly the same ratios as those of annual depths equate to the used seasonal (winter, spring, summer, autumn) and short term durations (maximum annual depths for 10 minutes, 6 hours, 1 day) of the precipitation values. Evaporation values range from about 1.2 to $4 \mathrm{~mm} /$ day in Salerno, while the values for Germany were derived from equation (1).

Results from the long-term simulation show that runoff can be reduced through a green roof by up to $57 \%$ in a Mediterranean climate whereas in an oceanic climate there can be a reduction of about $90 \%$ (compared to an impervious roof with $100 \%$ runoff). Best mitigation 
results were achieved in both climates for single events as well as for summer and spring seasons. The least efficiency was determined for the autumn season with an average runoff reduction of $64.4 \%$ for the oceanic climate and only $42.7 \%$ for the Mediterranean climate.

In part, these relative good results show the influence of evaporation intensity and of the parameter $W_{\max }$. The latter was chosen here with the maximum recommended value from Ref. [15] as $65 \%$. Thus, it is significantly higher than the calibrated value of the monitored green roof with $W_{\max }=(39 / 150=) 26 \%$.

\section{CONCLUSION AND PROSPECTS}

The described long-term experiments and study show that restoring the natural water balance in urban areas is basically possible. It requires a combination of components such as storm water infiltration and/or utilization as well as green roofs. These tools have to be designed to interact in multiple ways. Suggested improvements include: Linkage between a pitched roof and a green roof for better water supply in rain-scarce periods and for storm water retention at heavy rain events. Feeding of an infiltration facility or a storm water harvesting tank by overflowing storm water from green roofs can be recommended in general. Most of the improvements developed here may also help to make such measures more acceptable and attractive for (public as well as private) users.

For design purposes, hydrological green roof simulation models need to be further improved. Most relevant model component is the calculation of the evapotranspiration process. The simple approaches by Brandt [12] and Haude [13] showed significant shortcomings in this respect.

Presently, the measured data sets from the described long-term investigation are used intensively at the University of Salerno. There, a tool for planning purposes was developed that predicts hydrological green roof behaviour as a function of local meteorological variables only. The crucial evaporation process, usually considered as a water balance dependent variable, is replaced here by empirical relationships providing an a-priori assessment of soil water losses through actual evaporation [17]. Even if the modelling scheme appears to offer a great potential, it still needs to be verified for different green roof systems and climate conditions. For this purpose, in spring 2017 at the campus in Salerno two experimental test beds with different drainage systems and local vegetation were implemented.

\section{REFERENCES}

[1] Sartor, J., Sustainable Urban Storm Water Management. Final Project Report (in German). Trier University of Applied Sciences, Germany, 2017.

[2] German Water Association (DWA). Standard A 100 - Guideline of integrated urban drainage, 2006.

[3] DWA. Draft of standard A 102 - Fundamentals of Management and Treatment of Storm Water to be Discharged in Water Courses, 2016.

[4] German Association of Sewage Technology, Storm water management in urban areas to approximate natural flow conditions. (in German), Korrespondenz Abwasser, 4(46), pp. 575-580, 1989.

[5] Sartor, J., The significance of the water balance in sustainable storm water management. Flood control today - sustainable water management (in German), eds. S. Heiden, R. Erb, \& F. Sieker, Erich Schmidt Publishers, Berlin, pp. 287-308, 2001

[6] Meßer, J. \& Gall, S., Matched storm water infiltration as compensation for the interference to the groundwater recharge due to building development (in German). Korrespondenz Abwasser, 1 (63), pp. 22 - 27, 2016 
[7] Schlichtig, B., Dittmer, U., Haas, U., Besler, H., Langner, J., Henrichs, M. \& Uhl, M., Steps to a flexible management of the urban water cycle (in German). Wasser und Abfall, 4(57), pp. 10-15, 2014

[8] Sartor, J., Is storm water infiltration from developed areas really sustainable? (in German) Wasser und Abfall, 7-8(4), pp. 24-28, 2002.

[9] German Standard: DIN 1989 - Storm water utilization facilities, 2002.

[10] Uhl, M., Schiedt, L., Henneberg, M., Mann, G., Long-term study about flow behavior of green roofs (in German). Wasser und Boden, 3(55), pp. 1-20, 2003.

[11] Scherer, I., Henrichs, M., Uhl, M., Schuetz, T., Weiler, M., Hackenbroch, K., König, F. \& Freytag, T., Planning tools and management concepts for the water resources in urban areas (in German). Korrespondenz. Wasserwirtschaft, 4(10), pp. 221-228, 2017.

[12] DWA: Advisory guideline ATV-DVWK-M 165 - Requirements for storm-runoffcalculations in urban drainage, 2003.

[13] DWA: Advisory guideline DVWK-M 238 - Determination of evaporation from land and water surfaces, 1996.

[14] Meteorological station Brauneberg; Agrarmeteorologie Rheinland-Pfalz, available at www.am.rlp.de

[15] The Landscaping and Landscape Development Research Society eV. (FLL): Guideline for the Planning, Execution and Upkeep of Green-Roof Sites, 2008.

[16] Mobilia, M., Longobardi, A. \& Sartor, J., Green roofs hydrological performance under different climate conditions; WSEAS Transactions on Environment and Development, 2015, available at http://wseas.org/wseas/cms.action?id=10179

[17] Mobilia, M., Longobardi, A. \& Sartor, J., Including a-priori assessment of actual evapotranspiration for green roof daily scale hydrological modelling. MDPI water, 2017, available at www.mdpi.com/journal/water 